\title{
A Comparison between a Classical and a Modified Root Fillet
}

\author{
Norbert HODGYAI, ${ }^{1}$ Ferenc TOLVALY-ROȘCA, ${ }^{2}$ Márton MÁTÉ ${ }^{3}$ \\ Sapientia Hungarian University of Transylvania, Faculty of Technical and Human Sciences, \\ Department of Mechanical Engineering, Târgu Mureș, Romania \\ ${ }^{1}$ hodgyai@ms.sapientia.ro \\ 2tferi@ms.sapientia.ro \\ ${ }^{3}$ mmate@ms.sapientia.ro
}

\begin{abstract}
The main purpose of this paper consists in improving the rigidity of the gear tooth by applying various root fillet forms that differ from the classical $0.38 \mathrm{~m}$ radius circle arc. During the research the necessity of the re-formulation of the undercut appeared. It appears much later in case of applying rounded addendum edge planing comb as in case of using a classic generating profile tool. Therefore, the limits of the profile shifting can be significantly extended without weakening the tooth dedendum.

The paper presents the stress repartitions under equal load, which occur on classic teeth, and on teeth having a modified root fillet. In this last case, the modified root fillet is the envelope of the curve family constituted by the rounded edge curves, in the relative motion of the comb related to the cut gear.
\end{abstract}

Keywords: gear, root fillet,stress analysis, deformation, rigidity.

\section{Introduction}

Considering the theory of the involute curve generation, the cylindrical wheel meshing tools, classifying them upon their generating principle, can be divided into two categories:

- generating tools working respecting the standing-line method - these are the planing combs;

- generating tools working with respect to the moving-line method - gear hobs, Fellow's cutter and the skiving cutter [1].

The rack-type tool produces the most accurate involute profile because the kinematic connection of the rack-and-pinion is equivalent to the movement of a straight line rolled on a circle, and the straight edge shapes can always be produced more precisely than edges from curved surfaces. If the tool pitch line is rolled down on the wheel's pitch circle without slipping, the rack tooth profile's normal remains tangent to the base circle, and the meshing curve of the manifold of edge tracks in different relative positions becomes the tooth profile of the manufactured wheel. In this case, the manifold of meshed curves are the straight line segments of the rack tooth. This is one of the reasons the use of involute profiled teeth has become widespread. Despite of the fact rack-type tool can be manufactured at low costs and highest precision, the kinematic chains of the gear hobbing Maag or Sundeland-type machine tools are as complex as possible.

The basic profile of the generating rack for involute profiled cylindrical gears, according to DIN 867-1986, is presented in Figure 1.

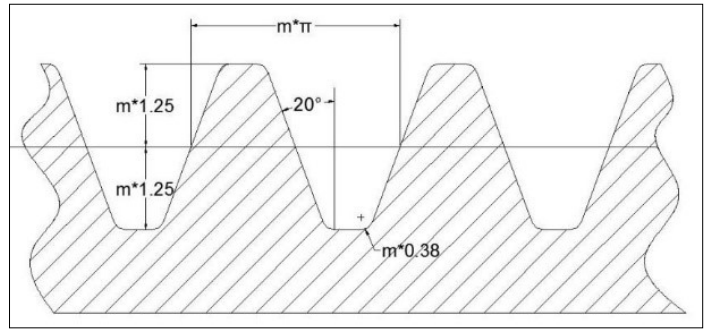

Figure 1. The generating rack. 
According to the research goal, we choose the most precise generating tool profile for the basic tool, and then we modified it with the addendum edge-flank edge fillet value. The profile generated with the modified tooth head is loaded in identical conditions (material quality, load force, same base surface in virtual space) to the classic profile. Stress analysis is used to acquire information regarding the behaviour of a tooth made with the tooth profile based on our recommendation, compared to a tooth addendum presenting a smaller fillet - used in practice.

\section{The mathematical model}

\subsection{The parametric equations of the tooth curve}

The tooting procedure lays on the basic geometric model illustrated in Figure 2.

The generating rack tooth profile is symmetric to the centreline. The figure shows the following 5 coordinate systems:

$-X_{0} P Y_{0}$ - the fixed coordinate system, whose $P X_{n}$ axis is tangent to the pitch circle;

- $X_{1}^{(0)} O_{1}^{(0)} Y_{1}^{(0)}$ - the coordinate system fixed to the rack, at the starting moment of the motion;

$-X_{1} O_{1} Y_{1}$ - the rack attached frame after a rotation of $\varphi$ angle of the cut wheel;

$-X_{2}^{(0)} O_{2}^{(0)} Y_{2}^{(0)}$ - the coordinate system fixed to the wheel at the starting moment of the motion;

$-\mathrm{X}_{2} \mathrm{O}_{2} \mathrm{Y}_{2}$ - the wheel's frame after a rotation of angle $\varphi$.

During the tooting process, the tooting rack removes the material within the contour of the tool tooth profile. This is interpreted in the modelling as the profile that results as the envelope of a curve family, mapped by the edges of the rack, during the relative motion.

The computing of the equations of the tooth profile requires some work in the gear system.

The easiest way to write the profile of the rack is in its own system. Then, it is transposed into the gear system as follows:

$$
\mathbf{r}_{2}=\mathbf{M}_{21} \mathbf{r}_{1}
$$

After some calculus, the transformation matrix takes the following form:

$$
\begin{aligned}
\mathbf{M}_{21} & =\left(\begin{array}{cccc}
\cos \varphi & -\sin \varphi & 0 & a_{14} \\
\sin \varphi & \cos \varphi & 0 & a_{24} \\
0 & 0 & 1 & 0 \\
0 & 0 & 0 & 1
\end{array}\right), \\
a_{14} & =r_{0} \varphi \cos \varphi-\left(r_{0}+m \xi\right) \sin \varphi \\
a_{24} & =r_{0} \varphi \sin \varphi+\left(r_{0}+m \xi\right) \cos \varphi
\end{aligned}
$$

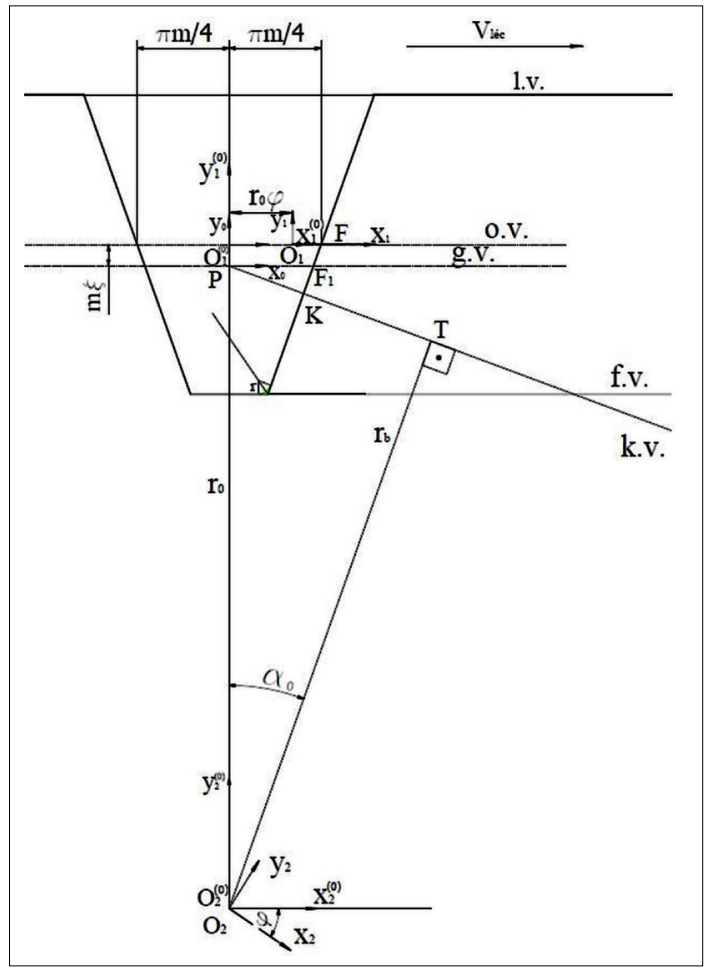

Figure 2. Geometry of generating.

The equation of meshing [2] is written and solved in the coordinate system of the rack:

$$
\mathbf{v}_{1}^{(12)} \times \mathbf{n}_{1}=0
$$

The quantities in equation (3) are expressed as follows, for an angular velocity value of $\omega=-1$ :

$$
\begin{aligned}
& \mathbf{v}^{(12)}=\mathbf{v}^{(1)}-\mathbf{v}^{(2)} \\
& \mathbf{v}_{1}^{(1)}=\left(\begin{array}{lll}
r_{0} \omega & 0 & 0
\end{array}\right)^{T}=\left(\begin{array}{lll}
r_{0} & 0 & 0
\end{array}\right)^{T} \\
& \underline{\mathbf{v}}_{1}^{(2)}=\left[\begin{array}{c}
y_{1}+r_{0}+m \xi \\
-x_{1}-r_{0} \varphi \\
0
\end{array}\right]
\end{aligned}
$$

Using the components of the normal vector $\left(n_{x} n_{y} 0\right)$ the general form of the rack-wheel meshing equation is as follows:

$$
\left(y_{1}+m \xi\right) n_{x}+\left(x_{1}+r_{0} \varphi\right) n_{y}=0
$$

The equation of meshing is used to write up the analytical tooth curve. The position of the coordinate systems is shown in Figure 3. The equations of the rounded profile of the generating rack in the rack system are the following:

$$
\left\{\begin{array}{l}
x_{1}(u)=x_{C}+r \cos \left(\alpha_{0}+u\right) \\
y_{1}(u)=y_{C}-r \sin \left(\alpha_{0}+u\right)
\end{array}\right.
$$




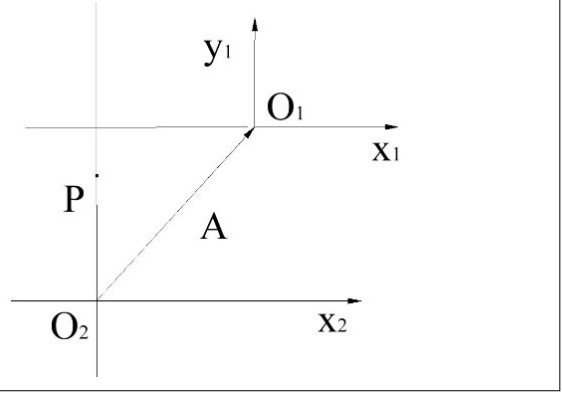

Figure 3. The relative position of coordinate systems.

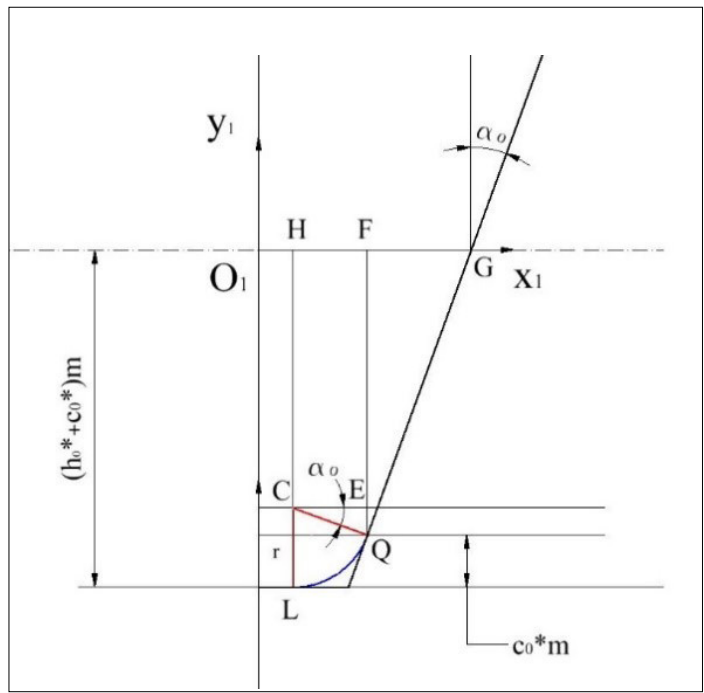

Figure 4. The computing of the coordinates of the addendum fillet arc centre $C$.

The normal vector of the circular arc can be written as:

$$
\underline{\mathbf{n}}(u)=\left(\begin{array}{lll}
\cos \left(\alpha_{0}+u\right) & \sin \left(\alpha_{0}+u\right) & 0
\end{array}\right)^{T}
$$

The detailed computing of the limits of the circular arc fillet can be found in [3] ban. The maximum possible value of the radius is calculated from the condition that the extent of the arc in the direction of the tooth height, does not exceed the $c=0,25 \mathrm{~m}$ standard dedendum clearance-value. Based on this, the value of the largest possible specific radius becomes:

$$
r_{\text {max }}^{*}=\frac{c_{0}}{\cos \alpha_{0}} \operatorname{tg}\left(\frac{\pi}{4}+\frac{\alpha_{0}}{2}\right)
$$

Thus, the radius of the generating rack tooth addendum fillet must be calculated using the formula below:

$$
r=m \psi r_{\text {max }}, \psi \in(0,1)
$$

The coordinates of the center of the addendum fillet arc are the followings [3] (Figure 4):

$$
\left\{\begin{array}{l}
x_{1}^{C}=m\left(\frac{\pi}{4}-\left(h_{0}^{*}+c_{0}^{*}\right) \operatorname{tg} \alpha_{0}-\frac{\psi r^{*}}{\cos \alpha_{0}}\right) \\
y_{1}^{C}=\left(\psi r^{*}-\left(h_{0}^{*}+c_{0}^{*}\right)\right) m
\end{array}\right.
$$

Equations of the curves manifold, that will mesh the tooth root fillet, result from formulas (1), (2) and (8). After completing the operations, these result in the following form:

$$
\left\{\begin{array}{l}
x_{2}(u, \varphi)=A \cos \varphi+B \sin \varphi-r_{0}(\sin \varphi-\varphi \cos \varphi)- \\
\quad-m \xi \sin \varphi \\
y_{2}(u, \varphi)=A \sin \varphi+B \cos +r_{0}(\cos \varphi+\varphi \sin \varphi)+ \\
\quad+m \xi \cos \varphi \\
A=x_{C}+r \cos \left(\alpha_{0}+u\right) \\
B=y_{C}-r \sin \left(\alpha_{0}+u\right)
\end{array}\right.
$$

The meshing equation (7) is transformed in a simple homogeneous trigonometric equation, using the normal vector coordinates (10), which solution is, according to [3]:

$$
u(\varphi)=\left\{\begin{array}{l}
-\operatorname{arctg}(g(\varphi))-\alpha_{0}+\pi, \varphi \leq \varphi_{k r} \\
-\operatorname{arctg}(g(\varphi))-\alpha_{0}, \varphi>\varphi_{k r}, \\
g(\varphi)=\left(y_{1}^{C}+m \xi\right) /\left(x_{1}^{C}+r_{0} \varphi\right)
\end{array}\right.
$$

\subsection{The analysis of the contact point of the root fillet and the involute profile}

The use of the root fillet parametric equations, due to the complexity of the expression (13) of the meshing equation solution, is difficult to apply. In order to build-up the solid model of the meshed tooth, it is necessary to determine the contact point between the theoretical involute tooth profile and the real tooth root fillet. This point is called the involute start point, and it is located on the involute start circle. The geometric construction used in [4] can also be applied to the rounded generating rack. The present study considers only the analysis of cases over the limit of the undercut, thus the tooth root fillet and the involute curve are tangent, avoiding the undercut proofing intersecting.

\subsubsection{Geometric notation of the involute}

The sense of Figure 5 can be perceived correctly when Figure 6 is also considered. The root fillet and the involute are tangent in point $A_{1}=A_{2}$. Point " $\mathrm{A}_{1}$ " is generated by point " $\mathrm{A}$ " of the generating tool's addendum fillet point, while point " $\mathrm{A}_{2}$ " is generated by the first point of the straight edge segment that coincides with A. (Figure 5). Since 
the end point of the straight segment and the start point of the fillet arc coincide, and the two curves are connected, they have a common tangent at that point. Thus, they must admit a common normal vector. This means that the curves mentioned above create the point of the meshed profile, located on the involute start circle, at the same time.

\subsubsection{The computing of the involute start cir- cle, using the line of action}

In Figure 6 the PBE centreline and its perpendicular in point $\mathrm{T}$, situated on the basic circle, are intersecting in $\mathrm{O}_{2}$ centre point, therefore $O P=r_{0}$ and $O T=r_{b}$.

Figure 6 helps to deduce directly the following geometric relations:

$$
\begin{aligned}
& P B=m\left(h_{0}+c_{0}-\xi\right)-m \psi r^{*}\left(1-\sin \alpha_{0}\right) \\
& A A_{1}=B A_{1}-B A=m\left(h_{0}+c_{0}-\xi-\psi r^{*}\right) \operatorname{ctg} \alpha_{0}
\end{aligned}
$$

The angular parameter value, when point $\mathrm{A}$ is coupling, can be computed as the quotient of length $\mathrm{AA}_{1}$ and the pitch circle radius:

$$
\varphi_{A}=\frac{A A_{1}}{r_{0}}=\frac{2\left(h_{0}+c_{0}-\xi-\psi r^{*}\right) \operatorname{ctg} \alpha_{0}}{Z}
$$

The radius of the involute start circle results from the triangle $O T A_{1}$ based on [4] and the notation used in Figure 6. The detailed deduction is omitted here.

The equations derived from the mathematical generation of the theoretical involute, based on the notations of Figure 7, are as follows:

$$
\left\{\begin{array}{l}
x(v)=r_{b}(\sin (\varepsilon+v)-v \cos (\varepsilon+v)) \\
y(v)=r_{b}(\cos (\varepsilon+v)+v \sin (\varepsilon+v))
\end{array}\right.
$$

Here $\varepsilon$ represents the half of the tooth gap centre angle on the basic circle:

$$
\varepsilon=\frac{\pi}{2 z}-2 \frac{\xi}{z} \operatorname{tg} \alpha_{0}-i n v \alpha_{0}
$$

Knowing the involute start circle radius value $r_{t}$ the interval of the parameter $v$ can be computed using the expression of the polar radius length, easilv deductible from equations (17). Thus:

$$
r_{t} \leq r_{x} \leq r_{a} \Leftrightarrow \sqrt{\frac{r_{t}^{2}}{r_{b}^{2}}-1} \leq \varepsilon \leq \sqrt{\frac{r_{a}^{2}}{r_{b}^{2}}-1}
$$

In the same way, based on Figure 6 and considering Willis's theorem, it can be stated that in the starting position of the generating motion (corre-

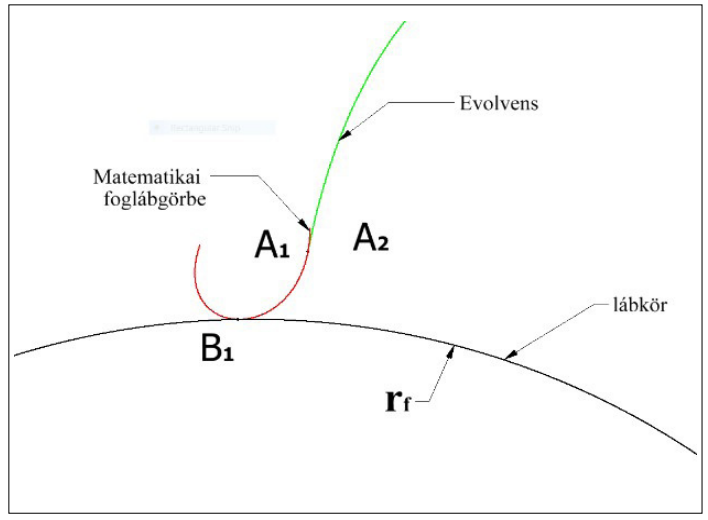

Figure 5. The connection of the tooth root fillet generated by the circular arc to the involute and the root circle.

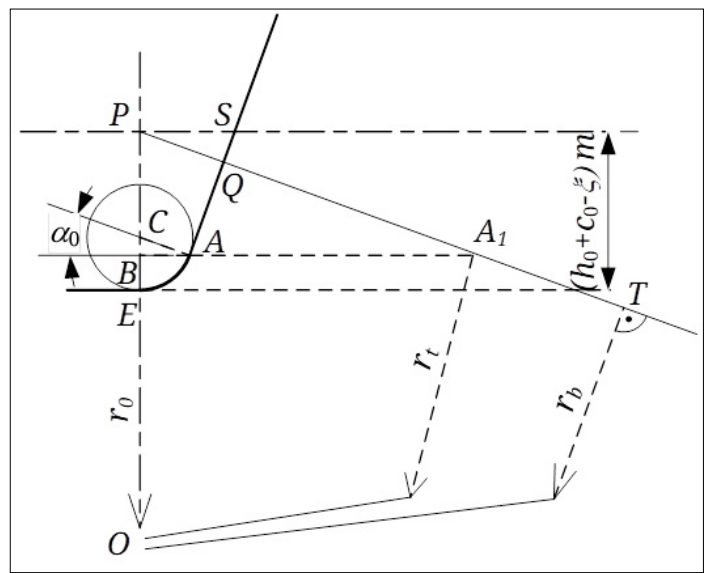

Figure 6. The definition of the involute start circle radius while using a rounded head rack type tool.

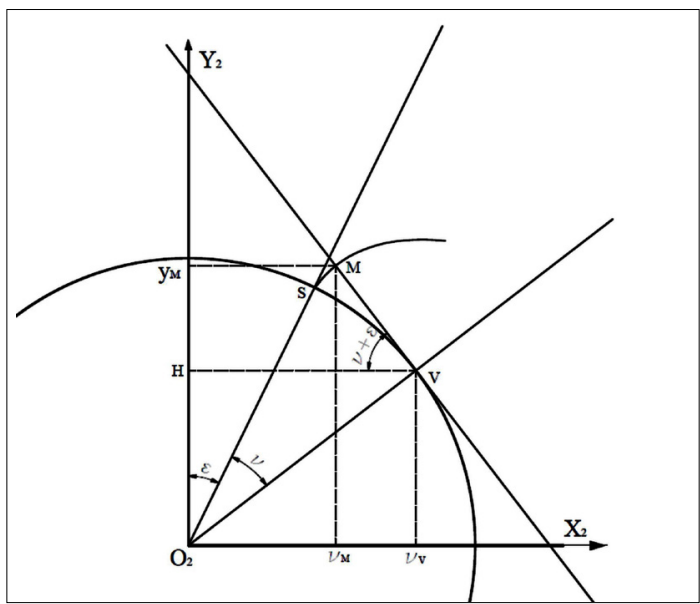

Figure 7. Figure used for mathematical generation of the involute. 
sponding to the zero value of the motion parameter), two different points are in generating position: the first and well known is the point $Q$ of the straight profile, while the other is the point $E$ of the circular arc $A E$.

It can be concluded from the figure that the tooth root fillet curve, and the involute flank, are meshed simultaneously: while the involute profile is generated in the direction defined by the decrease of the polar radius, the tooth root fillet builds-up from the root circle to the involute start circle, meaning the opposite sense..

From those stated above it can be concluded that the tooth root fillet equations are to be written using equations (14) and (16) of the envelope by running the parameter $\varphi$ in the $\left[0, \varphi_{\mathrm{A}}\right]$ interval.

\subsection{The generated curves}

The generated curves were plotted in Mathcad 15 environment (Figure 8), using the equations presented before. The following parameters were considered:

- module: $50 \mathrm{~mm}$;

- rack profile angle: $20^{\circ}$;

- specific addendum height: 1 ;

- specific foot clearance: 0.25 ;

- number of teeth: 18 ;

- profile shift factor: 0 .

The maximum value of the specific radius is set at 0.38 . This is the maximum rounding radius used at the $1 \mathrm{~mm}$ modulus planning comb. It is denoted here by "rcs".

Here, it must be emphasized that current modelling uses the specific rounding radius factor: this was set at 0.79 .

The variable $\varphi$ in the meshing process, reaches the value of $90^{\circ}$ and with this, the $\operatorname{tg}(\varphi)$ value becomes senseless. To overstep this inconvenience, the tooth root fillet was built-up of 3 segments. In the first segment of the root fillet results for $\varphi<90^{\circ}$ values. The next segment is obtained for $\varphi>90^{\circ}$ values. Finally, the missing point results for $\varphi=90^{\circ}$.

The common point of the involute arc and the root fillet lays on the involute start circle. Coordinates of this can be computed by equalizing the polar radii expressions of the geometric involute and the root fillet:

$$
\begin{aligned}
& x^{2}+y^{2}=\rho^{2}=r_{b}^{2} \cdot\left(1+\varphi^{2}\right) \\
& x^{2}(\varphi, u(\varphi))+y^{2}(\varphi, u(\varphi))=r_{b}^{2} \cdot\left(1+\varphi^{2}\right) \\
& \varphi \in\left[\varphi_{1}, \varphi_{2}\right]
\end{aligned}
$$

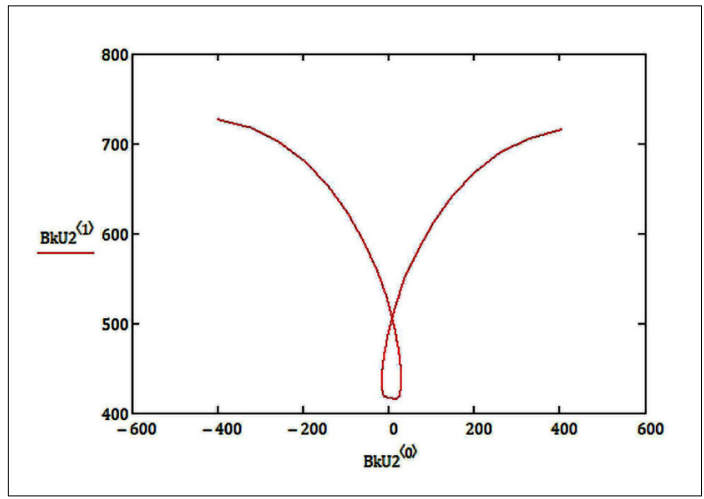

Figure 8. Illustration of the whole continuous root filet curve.

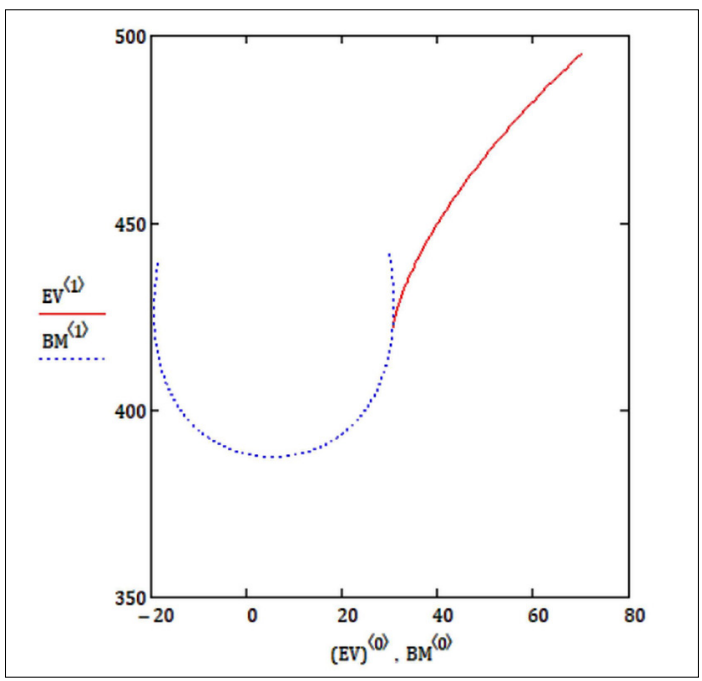

Figure 9. The involute arc and the tooth root fillet.

Since the start- and endpoint of the plotted tooth root fillet exceed the real arc limits, a correction in the program sequence is applied (Figure 9). The corrected arcs are represented in Figure $\mathbf{1 0 .}$

The coordinates of points generated by Mathcad, were saved in an excel file and then read with AutoCad. After drawing the characteristic circles, the tooth profile was represented and mirrored over the tooth symmetry line. Finally, the excess line segments were removed to obtain a complete tooth and the root circle (Figure 11).

The magnitude of the error occurred while connecting of the root circle and the tooth root fillet was compensated by increasing the root circle radius. During the stress analysis, this error leads to a negligible difference. 


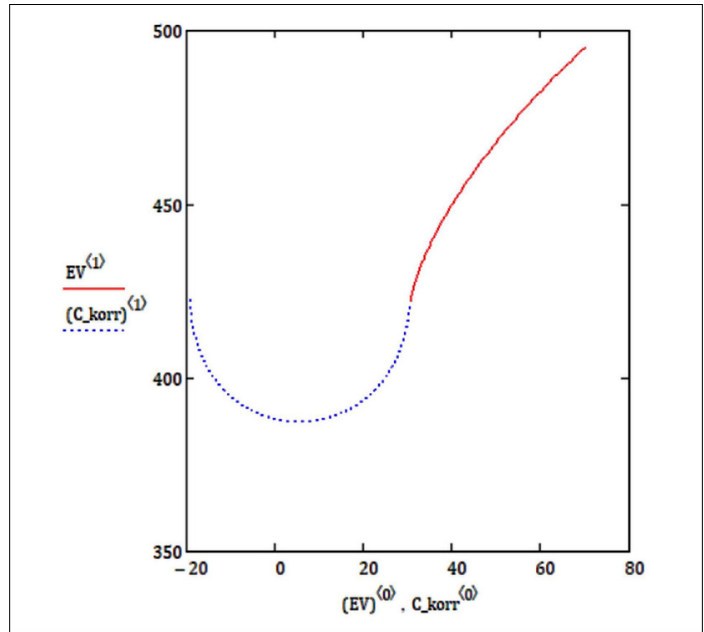

Figure 10. The final involute and tooth root fillet profile.

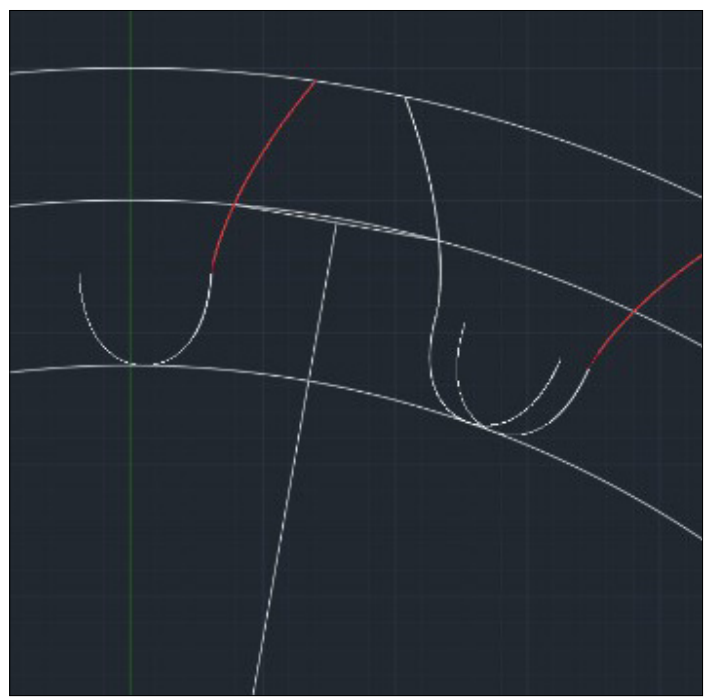

Figure 11. Profile generated by AutoCad.

The drawing model was converted to a solid model using the AutoDesk Inventor environment. Due to a communication error between the two used software packages, the profile taken from AutoCad was interpreted by Inventor as a non-continuous entity. Thus, the smoothing of the profile becomes necessary. This could not be done inside the Inventor environment.

This problem was solved using SolidWorks; the profile was smoothed with $1 \cdot 10^{-5}$ accuracy. Finally, a continuous surface was obtained as it is shown in Figure 13.

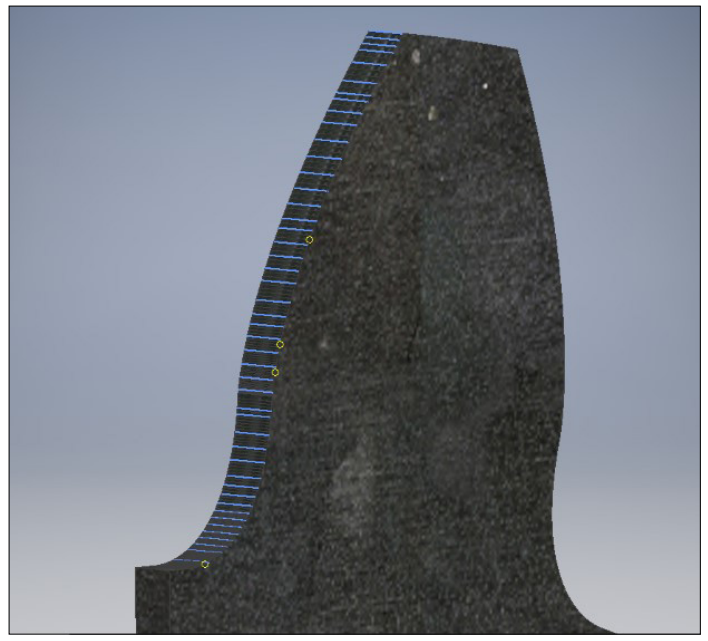

Figure 12. The tooth surface, consisting of several small surfaces.

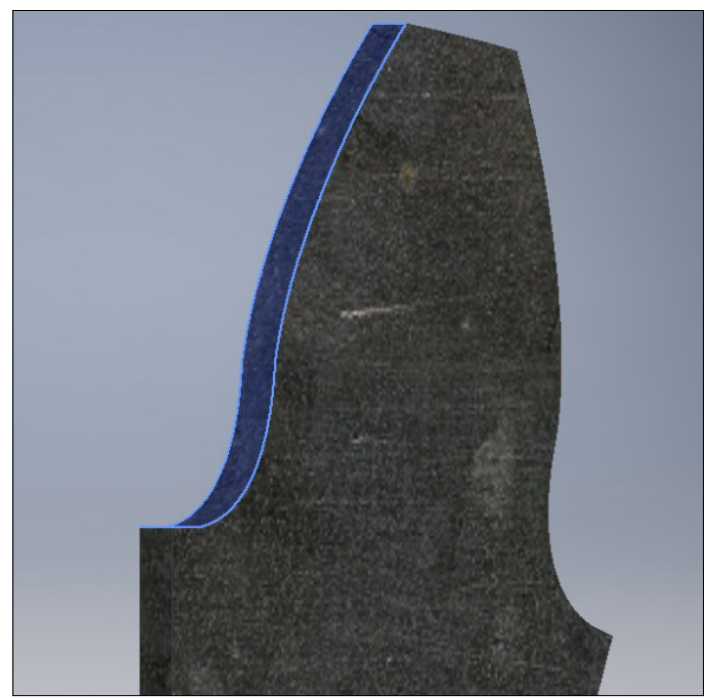

Figure 13. Continuous tooth surface approximated by a spline curve

\section{Stress analysis of a tooth realized using a classic planing comb}

In practice, a small rounding appears at the intersection of the tool flank and top land, which was taken as a circular arc with a radius of $0.02 \mathrm{~mm}$, during the modelling. Using the mathematical model presented above, the profile created in Mathcad was used to create the solid model in the Inventor environment. Its profile was smoothed in SolidWorks environment, admitting a deviation of $0.000456 \mathrm{~mm}$. The stress 


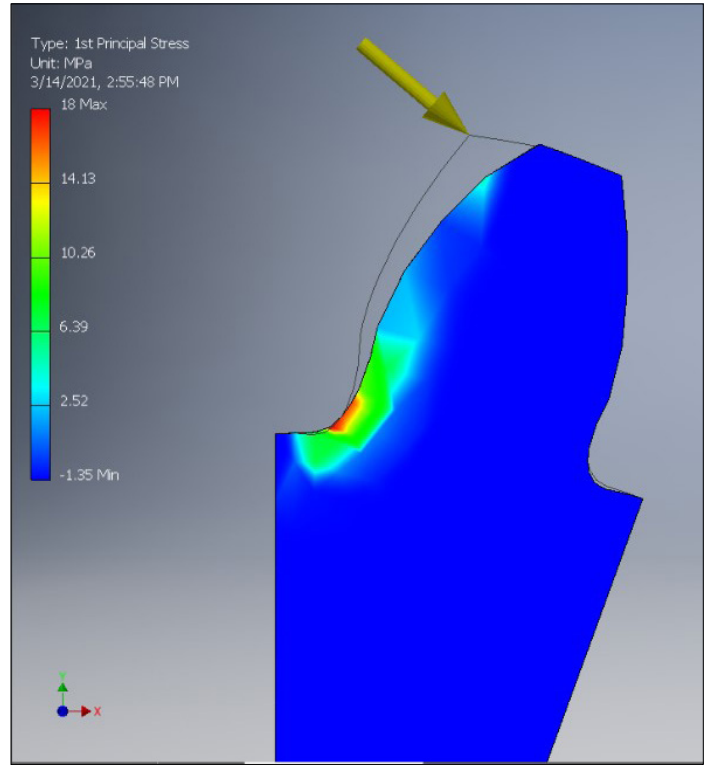

Figure 14. Distribution of the first principal stress.

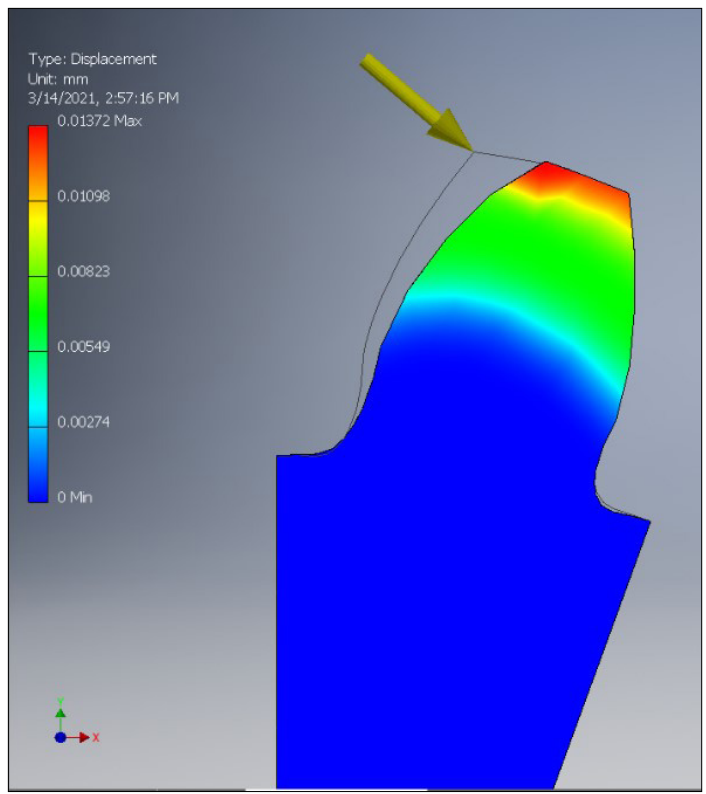

Figure 15. Representation of the largest displacements.

test was performed in the Inventor environment. Only a gear slice comprising one single tooth was considered. This solid is rigidly clamped on each side of the V-shape. The worst loading situation was assumed, i.e. the force acts on the apex of the profile.

The test results are shown in Figures 14 and 15.

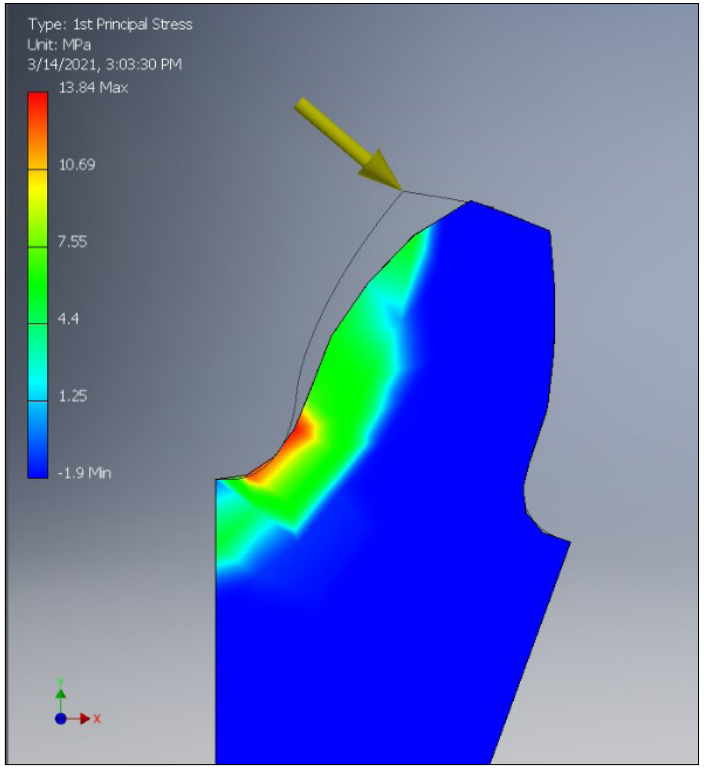

Figure 16. Distribution of the first principal stress.

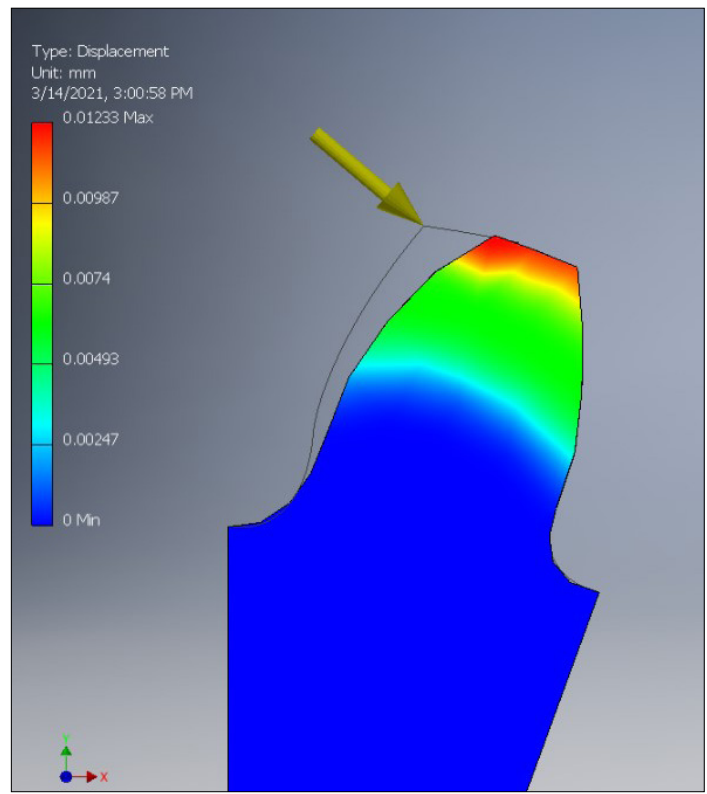

Figure 17. Representation of the largest displacements.

\section{Load analysis of the tooth generated by a rounded planing comb}

The model of the tooth, generated with a rounded addendum planing comb, was built up as described before. The load was applied under the same conditions. The results of the load test are shown in Figures 16. and 17. 


\section{Conclusions}

Comparing the corresponding diagrams of the stress distribution and the displacements, it can be observed that using a load force of a given direction and magnitude, and considering the same constraints of the solid model, the maximum displacement of the tooth was reduced by $10 \%$. This study has taken into consideration only simple wheels, without profile shift. It is supposed that more significant differences result when considering the teeth, generated at the limit values of the profile shifting.

In Figures 14 and 16 which show the first main stresses, it can be seen that the maximum stress in the root is 18 [MPa] for the standard profile and 13.84 [MPa] for the proposed profile. The stress distribution on the tooth side is much more uniform using the proposed curve.

Comparing Figures 15 and 17 which show the maximum displacements, it can be stated that in case of the standard profile the maximum displacement is 0.01337 [mm], while with the pro- posed tooth curve, only 0.01233 [mm]. Thus, the displacement value decreases with $10 \%$, in case of using the proposed root fillet.

\section{References}

[1] Máté M.: Hengeres fogaskerekek gyártószerszámai. Erdélyi Múzeum-Egyesület, Kolozsvár, 2016. 110-111. https://doi.org/10.36242/mtf-12

[2] Litvin F. L.: A fogaskerék-kapcsolás elmélete. Múszaki Könyvkiadó, Budapest, 1972.

[3] Hodgyai N, Tolvaly-Rosca F., Máté M.: Az alámetszés körülményei lekerekített gyártó fogasléc esetében. Müszaki Tudományos Közlemények, 14. (2020) 30-36. https://doi.org/10.33895/mtk-2021.14.05

[4] Szeniczei L.: Az általános fogazás. Műszaki Könyvkiadó, Budapest, 1955.

[5] Tolvaly-Roșca F., Máté M., Forgó Z., Kakucs A.: Development of Helical Teethed Involute Gear Meshed with a Multi-Edge Cutting Tool Using a Mixed Gear Teeth Modeling Method. Procedia Engineering, 181. (2017) 153-158. https://doi.org/10.1016/j.proeng.2017.02.421. 